\title{
Association between mild traumatic brain injury and mental health problems and self-reported cognitive dysfunction in Iraq and Afghanistan Veterans
}

\author{
Karen H. Seal, MD, MPH; ${ }^{1-2}$ Daniel Bertenthal, MPH; ${ }^{1}$ Kristin Samuelson, PhD; ${ }^{1,3}$ Shira Maguen, PhD; ${ }^{1-2}$ \\ Sant Kumar, BA; ${ }^{1}$ Jennifer J. Vasterling, $\mathbf{P h D}^{4}$ \\ ${ }^{1}$ San Francisco Department of Veterans Affairs (VA) Health Care System, San Francisco, CA; ${ }^{2}$ University of California, \\ San Francisco, San Francisco, CA; ${ }^{3}$ California School of Professional Psychology, Alliant International University, San \\ Francisco, CA; ${ }^{4}$ VA Boston Healthcare System, Boston, MA; and Boston University School of Medicine, Boston, MA
}

\begin{abstract}
The Department of Veterans Affairs traumatic brain injury (TBI) screening program is intended to detect and expedite treatment for TBI and postconcussive symptoms. Between April 14, 2007, and May 31, 2012, of 66,089 Iraq and Afghanistan Veterans who screened positive on first-level TBI screening and later completed comprehensive TBI evaluation that includes the Neurobehavioral Symptoms Inventory, 72\% reported moderate to very severe cognitive impairment (problems with attention, concentration, memory, etc.) that interfered with daily activities. This included $42 \%$ who were found not to have sustained combat-related mild TBI (mTBI). In contrast, 70.0\% received a posttraumatic stress disorder (PTSD) diagnosis and 45.8\% received a depression diagnosis. Compared with Veterans without mTBI, PTSD, or depression diagnoses, the lowest risk for self-reported cognitive impairment was in Veterans with confirmed mTBI only; a greater risk was found in those with PTSD diagnoses, with the greatest risk in Veterans with PTSD, depression, and confirmed mTBI, suggesting only a weakly additive effect of mTBI. These findings suggest that Veterans with multiple mental health comorbidities, not just those with TBI, report moderate to very severe cognitive impairment. Mental health treatment for conditions such as PTSD and depression (with or without TBI) may result in improvements in cognitive functioning and/or include assessment and support for Veterans experiencing cognitive problems.
\end{abstract}

Key words: cognitive dysfunction, concussion, depression, mental health, mild traumatic brain injury, population-based screening, postdeployment, posttraumatic stress disorder, primary care, recovery expectations, Veterans.

\section{INTRODUCTION}

More than 2 million American men and women have served in the conflicts in Iraq and Afghanistan. Due to the high incidence of blasts, motor vehicle accidents, falls, and other combat-related injuries coupled with improved trauma care, traumatic brain injury (TBI) has been an unfortunately prevalent injury outcome of the current conflicts [1-2]. In published surveys of Iraq and Afghanistan Veterans and Active Duty infantry servicemembers, 12 to 23 percent have reported a history of TBI [2-3]. Using widely accepted diagnostic criteria, studies

\footnotetext{
Abbreviations: $\mathrm{ARR}=$ adjusted relative risk, $\mathrm{CI}=$ confidence interval, CTBIE = Comprehensive TBI Screening and Evaluation, ICD-9-CM = International Classification of DiseasesNinth Revision-Clinical Modification, $\mathrm{mTBI}=$ mild traumatic brain injury, NPCD = National Patient Care Database, NSI = Neurobehavioral Symptoms Inventory, OEF = Operation Enduring Freedom, OIF = Operation Iraqi Freedom, OND = Operation New Dawn, PTSD = posttraumatic stress disorder, $\mathrm{RR}=$ relative risk, $\mathrm{SSN}=$ Social Security number, $\mathrm{TBI}=$ traumatic brain injury, VA = Department of Veterans Affairs.

*Address all correspondence to Karen H. Seal, MD, MPH; San Francisco VA Medical Center, 4150 Clement St, Box 111A-1, San Francisco, CA 94121; 415-221-4810, ext 24852; fax: 415-750 6921. Email: Karen.Seal@va.gov http://dx.doi.org/10.1682/JRRD.2014.12.0301
} 
of civilians and Veterans have shown that of all TBI cases, 85 percent represent mild TBI (mTBI) [4].

Studies of civilian populations have revealed that TBI may result in acute postconcussive symptoms, including physical complaints such as headaches; emotional problems such as irritability; and cognitive concerns such as impaired attention, concentration, and memory [5]. In the majority of civilian cases, particularly in mTBI, these postconcussive symptoms resolve completely in days to months [6-7]. A minority of patients (approximately 10\%-20\%) continues to report nonspecific physical, emotional, and cognitive postconcussive symptoms months to years after the original injury [6-9]. Postconcussive symptoms have been associated with poor social and occupational functioning, including underemployment, low income, and marital and family problems [10].

Military service-related mTBI often occurs in the context of other combat-related trauma, and as such, mTBI is frequently associated with comorbid mental health disorders, especially posttraumatic stress disorder (PTSD) and depression [11-13]. In particular, postconcussive cognitive symptoms attributed to mTBI, such as trouble with memory and attention, have long been understood to overlap with symptoms of PTSD and depression [14-16]. Hoge et al. found that, of Operation Iraqi Freedom (OIF) servicemembers who reported mTBI with loss of consciousness for $<30 \mathrm{~min}, 44$ percent met criteria for PTSD and 23 percent met criteria for depression [2]. Moreover, Hoge et al. found that PTSD and depression explained part of the relationship (or statistical variance) between mTBI and memory and concentration problems [2], a finding that was replicated in a subsequent epidemiologic study [12].

In April 2007, the Department of Veterans Affairs (VA) introduced a stepped population-based screening program for mTBI to promote early detection and intervention in response to mounting public concern about TBI [17] As such, on presenting to a VA facility, OIF/ Operation Enduring Freedom (OEF)/Operation New Dawn (OND) Veterans (who have not already been told that they have a moderate to severe TBI) undergo firstlevel screening for mTBI, which is typically performed in primary care [18]. If the first-level TBI screen is positive for current symptoms, Veterans are referred for a comprehensive TBI evaluation by a trained VA TBI specialist, typically in a subspecialty clinic, to determine whether the current symptoms are due primarily to mTBI (or due to another clinical entity, such as PTSD) and to develop a treatment plan depending on diagnosis and presenting symptoms.

This comprehensive clinical evaluation of TBI is currently considered the "gold standard" for symptomatic mTBI diagnosis in the VA healthcare system. The 22item Neurobehavioral Symptoms Inventory (NSI) is performed as part of the comprehensive TBI evaluation and assesses for physical, emotional, and cognitive postconcussive symptoms [19]. Specifically, the NSI includes four items that measure different dimensions of Veterans' cognitive performance by self-report as well as the selfreported functional effect of the cognitive symptoms on daily activities.

This study focuses on one domain of postconcussive symptoms as measured by the four cognitive functioning items on the NSI and examines the relative association of self-reported moderate to very severe cognitive functioning with mTBI, PTSD, and depression. While mTBI has been shown to have unique effects on health and functioning [20-23], we focus on the overlap of mTBI with PTSD and depression because these most commonly present together, and cognitive complaints are important overlapping features of all three conditions [11-16]. We hypothesize that self-reported cognitive symptoms that adversely affect daily functioning at the level of moderate to very severe are more strongly associated with individual mental health disorders and with mental health disorders in conjunction with mTBI than with mTBI alone. Further, we investigate the interactive relationships among these disorders with respect to self-reported cognitive functioning and suggest a practical modification of the current VA TBI screening program that may expedite targeted counseling and care for returning combat Veterans.

\section{METHODS}

\section{Study Population}

This retrospective cohort of OIF/OEF Veterans was identified using the VA Comprehensive TBI Screening and Evaluation (CTBIE) database. First-level TBI screening is repeated each time a combat Veteran completes a deployment and returns to a VA healthcare facility; for Veterans with multiple deployments, we used the last and most current CTBIE data. In order to screen positive on the VA first-level TBI screen, Veterans must have 
endorsed all four items: (1) a TBI injury mechanism, (2) problems that started immediately after the injury, (3) problems that began or got worse after the injury, and (4) the presence of one or more postconcussive symptoms (i.e., memory problems, balance problems or dizziness, sensitivity to bright light, irritability, headaches, and sleep problems) in the $7 \mathrm{~d}$ prior to TBI screening [17]. As soon as one of the items is not endorsed, the TBI screen terminates and is considered negative, resulting in many Veterans never being asked about current postconcussive symptoms (since this is the last item) or not being referred for comprehensive TBI evaluation.

Figure 1 shows that of 539,007 OIF/OEF Veterans who underwent first-level TBI screening between April 14, 2007, and May 31, 2012, 111,503 (20.7\%) screened positive on the first-level TBI screen and were referred for comprehensive TBI evaluation. Veterans were excluded from the analytic cohort if they screened negative on first-level evaluation ( $n=427,504)$, if they screened positive for mTBI but failed to attend the comprehensive TBI evaluation at a VA facility, if the results of their comprehensive evaluation were not entered in the CTBIE database ( $n=40,715)$, or if their results were considered indeterminate with respect to TBI diagnosis ( $n=$ 4,506). In addition, we excluded 193 Veterans who lacked complete data. This resulted in an analytic cohort of 66,089 OIF/OEF Veterans who had complete data from the comprehensive TBI evaluation with a binary clinical determination as to whether their symptoms were consistent with a diagnosis of mTBI or not (Figure 1).

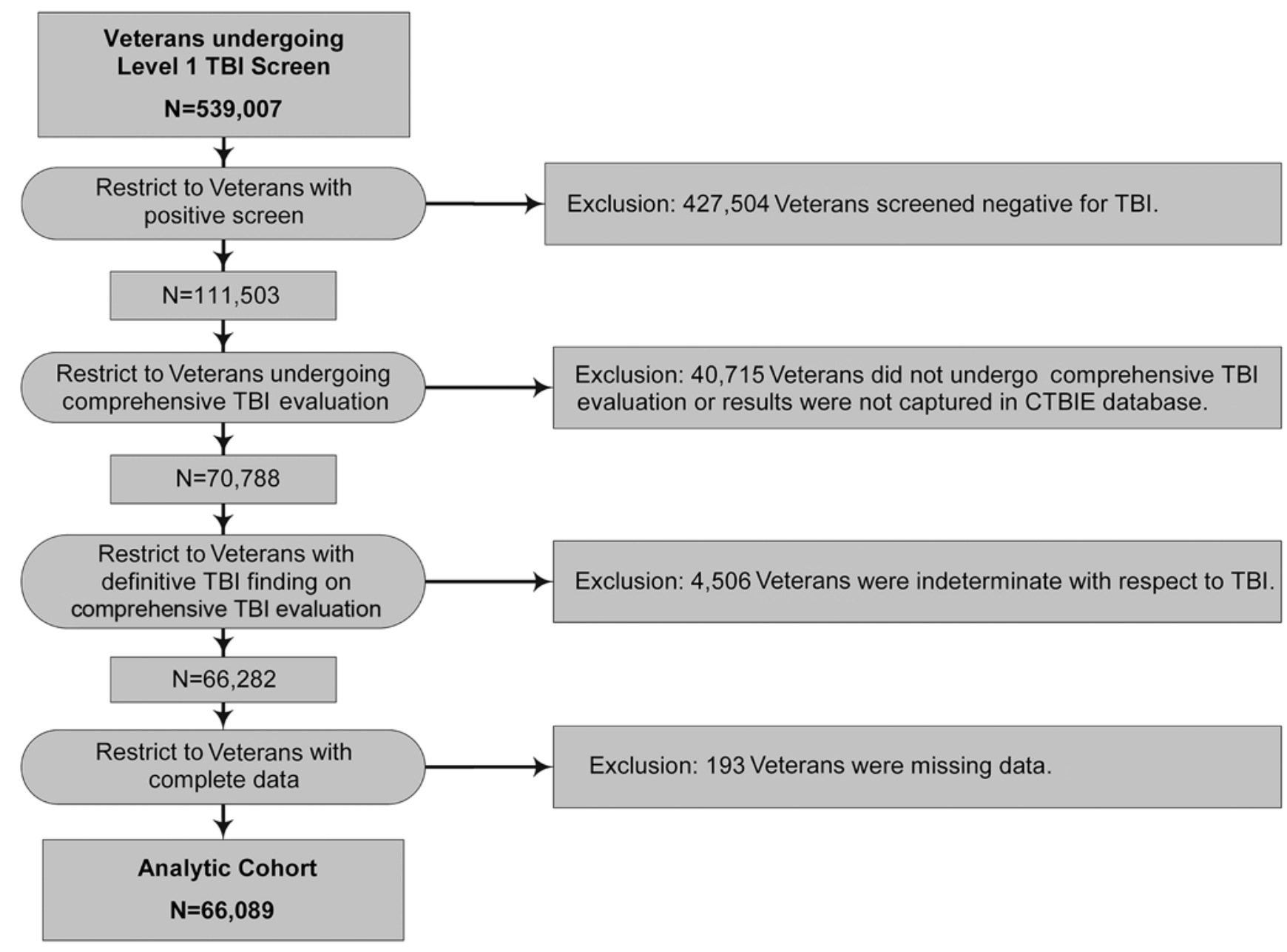

Figure 1.

Flowchart showing derivation of analytic cohort after applying study inclusion and exclusion criteria. CTBIE = Comprehensive TBI Screening and Evaluation, TBI = traumatic brain injury. 


\section{Data Source}

The main data source was the VA CTBIE database, an accruing national database of OIF/OEF Veterans who have enrolled in VA healthcare and have undergone at least one VA first-level TBI screen since April 14, 2007, when the VA TBI screen was first introduced. The CTBIE database contains the following data elements: identification of OIF/OEF Veterans undergoing first-level VA TBI screening using scrambled Social Security numbers (SSNs); individual-level results of the first-level VA TBI screen (positive or negative); identification of Veterans who completed the comprehensive TBI evaluation (among those who screened positive on the first-level TBI screen); and detailed results of the comprehensive TBI evaluation performed by a trained VA TBI specialist (e.g., neurologist or equivalent), including (1) information about TBI event(s), (2) postconcussive symptoms from the 22-item NSI, and (3) final determination of mTBI diagnosis. We used Veterans' scrambled SSNs to link CTBIE data to other VA national databases: (1) the VA OIF/OEF/OND Roster, containing basic individuallevel sociodemographic and military service information about Veterans of OEF (primarily Afghanistan), OIF (primarily Iraq), and OND (the new designation for OIF after September 1, 2010); (2) the VA National Patient Care Database (NPCD), containing VA healthcare utilization data (i.e., date of VA clinic visit and associated diagnosis(es) designated using International Classification of Diseases-Ninth Revision-Clinical Modification (ICD-9CM) codes); (3) the VA Decision Support System, used to extract individual-level pharmacy data; and (4) the VA Planning System Support Group, for distances from patient residence to VA facilities.

\section{Study Variables}

\section{Dependent Variables}

The 22-item NSI has been used in Veterans [24]. The main binary dependent variable was self-reported "cognitive impairment" rated as either "none or minimal" versus "moderate to very severe" on the NSI during comprehensive TBI evaluation. Self-reported moderate to very severe cognitive impairment was defined as endorsing two of the four cognitive items on the NSI (i.e., poor concentration and cannot pay attention; forgetfulness and cannot remember things; difficulty making decisions; and slowed thinking, difficulty getting organized, and cannot finish things) at the level of 2 to 4 (on a
Likert scale from 0-4), in which any response $\geq 2$ indicated a cognitive deficit that progressively impaired daily function (from moderate to very severe effect on daily activities). We a priori developed this algorithm for selfreported cognitive impairment based on expert consensus of five experienced VA staff neuropsychologists who work with Veterans with TBI and comorbid mental health problems. The threshold of $\geq 2$ was selected because at this level, self-reported cognitive impairment was described as impairing functioning.

\section{Independent Variables}

The main independent variables were individual and combinations of mental disorder diagnoses, i.e., confirmed TBI (from comprehensive TBI evaluation), PTSD (ICD-9-CM code 309.81), and depressive disorders (ICD-9-CM codes 296.20-296.25, 296.30-296.35, 300.4 , and 311 [NPCD]), which were ascertained on at least two separate occasions in the period from $1 \mathrm{yr}$ before to 1 yr after the index TBI diagnosis. Potential confounding covariates included (1) sociodemographic characteristics, which included a crude designation of race and ethnicity, and residence, defined as rural versus urban based on distance to the nearest VA facility; (2) military service characteristics, which included a combined variable of rank and education since the two were highly correlated, and number of deployments (single vs multiple); and (3) other health problems, such as alcohol abuse and dependence (ICD-9-CM codes 305.00-305.03 and 303), drug abuse and dependence (ICD-9-CM codes 305.20-305.93 and 304), and prescription medications that might negatively affect cognitive function, i.e., opioid and benzodiazepine and/or sedativehypnotic medications. As a secondary subanalysis to roughly gauge the validity of self-report, we examined the association of self-reported cognitive dysfunction with proxies for mTBI-related severity (as reported during the comprehensive TBI evaluation), i.e., number of blasts and other injuries resulting in TBI and severity of the injury (number of episodes of loss of consciousness or posttraumatic amnesia). In fact, we found a positive correlation between self-reported cognitive dysfunction and the level of TBI severity reported on the NSI (Table 1).

\section{Statistical Analyses}

For the main study population of 66,089 Veterans, we first determined the proportion that endorsed cognitive dysfunction at a level of moderate to very severe corresponding 
Table 1.

Unadjusted association of self-reported cognitive impairment with mental disorder diagnoses and injury characteristics in 66,089 Iraq and Afghanistan Veterans who screen positive for traumatic brain injury (TBI) and comprehensive TBI evaluation (April 14, 2007-May 31, 2012).

\begin{tabular}{cccccc}
\hline Mental Disorder & All Veterans & Minimal or No & Moderate to Severe & \\
$\begin{array}{c}\text { Diagnoses and Injury } \\
\text { Characteristic }\end{array}$ & $(N=66,089), n$ & $\begin{array}{c}\text { Cognitive Impairment } \\
(n=18,475), n(\%)\end{array}$ & $\begin{array}{c}\text { Cognitive Impairment } \\
(n=47,614), n(\%)\end{array}$ & RR (95\% CI) & $p$-Value \\
\hline
\end{tabular}

\begin{tabular}{|c|c|c|c|c|c|}
\hline \multicolumn{6}{|c|}{ Diagnoses (non-mutually exclusive) } \\
\hline \multicolumn{6}{|l|}{ Confirmed TBI } \\
\hline No & 27,533 & $9,880(35.9)$ & $17,653(64.1)$ & 1.00 (ref) & - \\
\hline Yes & 38,556 & 8,595 (22.3) & 29,961 (77.7) & $1.21(1.20-1.22)$ & $<0.001$ \\
\hline \multicolumn{6}{|l|}{ PTSD } \\
\hline No & 19,851 & $8,722(43.9)$ & $11,129(56.1)$ & 1.00 (ref) & - \\
\hline Yes & 46,238 & 9,753 (21.1) & 36,485 (78.9) & $1.41(1.39-1.43)$ & $<0.001$ \\
\hline \multicolumn{6}{|l|}{ Depression } \\
\hline No & 35,798 & $12,801(35.8)$ & 22,997 (64.2) & 1.00 (ref) & - \\
\hline Yes & 30,291 & $5,674(18.7)$ & 24,617 (81.3) & $1.27(1.25-1.28)$ & $<0.001$ \\
\hline \multicolumn{6}{|c|}{ Diagnoses (mutually exclusive) } \\
\hline No Diagnosis & 7,406 & $4,161(56.2)$ & $3,245(43.8)$ & 1.00 (ref) & - \\
\hline Confirmed TBI & 7,829 & $3,193(40.8)$ & $4,636(59.2)$ & 1.35 (1.31-1.39) & $<0.001$ \\
\hline PTSD & 7,779 & $2,679(34.4)$ & $5,100(65.6)$ & $1.50(1.45-1.54)$ & $<0.001$ \\
\hline Depression & 2,421 & 807 (33.3) & $1,614(66.7)$ & $1.52(1.46-1.58)$ & $<0.001$ \\
\hline $\begin{array}{l}\text { Confirmed TBI and } \\
\text { Depression }\end{array}$ & 2,195 & $561(25.6)$ & $1,634(74.4)$ & $1.70(1.64-1.76)$ & $<0.001$ \\
\hline PTSD and Depression & 9,927 & $2,233(22.5)$ & $7,694(77.5)$ & $1.77(1.72-1.82)$ & $<0.001$ \\
\hline Confirmed TBI and PTSD & 12,784 & $2,768(21.7)$ & $10,016(78.3)$ & $1.79(1.74-1.84)$ & $<0.001$ \\
\hline $\begin{array}{l}\text { Confirmed TBI, PTSD, } \\
\text { and Depression }\end{array}$ & 15,748 & $2,073(13.2)$ & $13,675(86.8)$ & $1.98(1.93-2.04)$ & $<0.001$ \\
\hline \multicolumn{6}{|c|}{ TBI-Related Injuries and Sequelae } \\
\hline \multicolumn{6}{|l|}{ Blast } \\
\hline 0 & 23,220 & $7,511(32.3)$ & 15,709 (67.7) & 1.00 (ref) & - \\
\hline 1 & 24,378 & $6,468(26.5)$ & $17,910(73.5)$ & $1.09(1.07-1.10)$ & $<0.001$ \\
\hline$\geq 2$ & 18,491 & $4,496(24.3)$ & $13,995(75.7)$ & $1.12(1.11-1.13)$ & $<0.001$ \\
\hline \multicolumn{6}{|c|}{ Other Injuries Contributing to TBI } \\
\hline 0 & 8,664 & $2,940(33.9)$ & $5,724(66.1)$ & 1.00 (ref) & - \\
\hline 1 & 18,054 & $5,811(32.2)$ & $12,243(67.8)$ & $1.03(1.01-1.05)$ & 0.005 \\
\hline$\geq 2$ & 39,371 & $9,724(24.7)$ & $29,647(75.3)$ & $1.14(1.12-1.16)$ & $<0.001$ \\
\hline \multicolumn{6}{|l|}{ Loss of Consciousness } \\
\hline 0 & 44,785 & $13,893(31.0)$ & $30,892(69.0)$ & 1.00 (ref) & - \\
\hline 1 & 16,685 & $3,854(23.1)$ & $12,831(76.9)$ & $1.11(1.10-1.13)$ & $<0.001$ \\
\hline$\geq 2$ & 4,619 & $728(15.8)$ & $3,891(84.2)$ & $1.22(1.20-1.24)$ & $<0.001$ \\
\hline \multicolumn{6}{|l|}{ Posttraumatic Amnesia } \\
\hline 0 & 48,443 & $15,362(31.7)$ & 33,081 (68.3) & 1.00 (ref) & - \\
\hline 1 & 13,237 & 2,610 (19.7) & $10,627(80.3)$ & 1.18 (1.16-1.19) & $<0.001$ \\
\hline$\geq 2$ & 4,409 & $503(11.4)$ & 3,906 (88.6) & $1.30(1.28-1.31)$ & $<0.001$ \\
\hline
\end{tabular}

to increasing negative effect on daily functioning for at least two of the four cognitive items on the NSI. Relative risks (RRs) with 95 percent confidence intervals (CIs) for selfreported moderate to very severe cognitive impairment in subgroups of Veterans were estimated using generalized lin- ear models with poisson distribution and robust error variance. We determined independent RRs for each mutually exclusive diagnostic category (confirmed TBI, PTSD, and depression) after adjusting for potential confounders. Specifically, adjusted models accounted for sociodemographic 
and military service characteristics (step 1), drug and alcohol use disorder diagnoses (step 2), and psychoactive prescription medication use (step 3). The final adjusted model allowed for 2- and 3-way interactions of TBI, PTSD, and depression. As a sensitivity analysis, we adjusted for number of mental health clinic visits to account for possible ascertainment bias but the adjustment did not produce clinically important changes in the risk estimates. Analyses were conducted using SAS 9.3 (SAS Institute Inc; Cary, North Carolina) and STATA 12.1 (Statacorp; College Station, Texas).

\section{RESULTS}

Despite having screened positive for mTBI, a large proportion of Veterans (36\%) were not referred for or did not attend their second-level comprehensive TBI evaluation. Tables 1 and $\mathbf{2}$ show the sociodemographic and military service characteristics, drug and alcohol problems, psychoactive medications, TBI and mental health diagnoses, and TBI-related injuries and sequelae in the 66,089 OIF/OEF Veterans who screened positive on first-level TBI evaluation and completed comprehensive TBI evaluation between April 14, 2007, and May 31, 2012. Of these Veterans, 5.8 percent were female; the median age was $28 \mathrm{yr}$ (interquartile range $=25-36 \mathrm{yr}$ ); 45.6 percent were ethnic minorities; 21.3 percent received an alcohol use disorder diagnosis; and 29.0 and 34.6 percent had received at least one prescription for an opioid medication and benzodiazepine, respectively, within $1 \mathrm{yr}$ of the index positive TBI screen.

Table 2 shows that being enlisted personnel (vs officer) with less education (high school only or only some college), having received alcohol and/or drug use disorder diagnoses, and having been prescribed opioids and/or benzodiazepines within $1 \mathrm{yr}$ of a positive TBI screen were associated with significantly increased risk for reporting moderate to very severe cognitive impairment in unadjusted models. Table 1 shows that there was also a corresponding increase in self-reported moderate to very severe cognitive impairment with an increasing number of blast injuries, other injury exposures that could result in TBI, and episodes of loss of consciousness and posttraumatic amnesia.

Of the 66,089 Veterans with positive TBI screen who completed the comprehensive TBI evaluation, 41.7 percent were found not to have sustained a combat-related
TBI. Of note, within $1 \mathrm{yr}$ of the index positive TBI screen, a full 70.0 percent received a PTSD diagnosis and 45.8 percent received a depression diagnosis. Table 1 reveals that only 11.8 percent of Veterans who screened positive for TBI and subsequently underwent comprehensive TBI evaluation received a clinical diagnosis of TBI alone. In contrast, nearly 50 percent with a confirmed TBI diagnosis also received diagnoses of PTSD and/or depression, with the majority of Veterans receiving $\mathrm{mTBI}$ and PTSD diagnoses or all three diagnoses (mTBI, PTSD, and depression).

Of those 66,089 Veterans who completed the comprehensive TBI evaluation, regardless of whether or not they received a confirmed diagnosis of mTBI, 47,614 (72.0\%) endorsed moderate to very severe cognitive impairment that had a negative effect on their daily activities. Moderate to very severe cognitive impairment was reported by 77.7 percent of Veterans with a confirmed mTBI diagnosis versus 64.1 percent who were found not to have a mTBI diagnosis $(\mathrm{RR}=1.21$; $95 \% \mathrm{CI}=1.20$ 1.22). Figure 2 shows the proportion of all Veterans reporting cognitive impairment symptoms at the level of moderate to very severe on the NSI. Overall, the most frequently reported cognitive symptoms were "forgetfulness, cannot remember things" (77\% reporting) and "poor concentration, cannot pay attention" (71\% reporting) (Figure 2). Figure 3 shows the prevalence and unadjusted RRs of reporting moderate to severe cognitive symptoms in association with non-mutually exclusive confirmed mTBI, PTSD, and depression diagnoses. Across mTBI, PTSD, and depression diagnoses, the proportions of Veterans reporting each of the cognitive impairment symptoms were relatively similar, although for each individual cognitive symptom, having a PTSD diagnosis (vs no PTSD diagnosis) was associated with a significantly greater RR for moderate to very severe selfreported cognitive impairment compared with mTBI and depression diagnoses.

Table 3 shows a clear progression of increasing risk of perceived moderate to very severe cognitive impairment by mental disorder status, even after fully adjusting for potential confounding variables. Compared with Veterans without these diagnoses, the lowest but independent risk for moderate to severe cognitive impairment was in Veterans with confirmed mTBI only (no PTSD and no depression) (adjusted RR [ARR] $=1.35$ ); with greater risk in those with PTSD diagnoses (no mTBI and no depression) $(\mathrm{ARR}=1.46)$; still greater risk in Veterans with PTSD and depression diagnoses (no mTBI) 
Table 2.

Association of self-reported cognitive impairment with selected characteristics in 66,089 Iraq and Afghanistan Veterans who screened positive for traumatic brain injury (TBI) and completed comprehensive TBI evaluation (April 14, 2007-May 31, 2012).

\begin{tabular}{|c|c|c|c|c|c|}
\hline Characteristic & $\begin{array}{l}\text { All Veterans } \\
(N=66,089), n\end{array}$ & $\begin{array}{c}\text { Minimal or No } \\
\text { Cognitive Impairment } \\
(n=18,475), n(\%)\end{array}$ & $\begin{array}{l}\text { Moderate to Severe } \\
\text { Cognitive Impairment } \\
(n=47,614), n(\%)\end{array}$ & RR (95\% CI) & $p$-Value \\
\hline \multicolumn{6}{|l|}{ Demographics } \\
\hline Female & 3,854 & $1,016(26.4)$ & 2,838 (73.6) & 1.00 (ref) & - \\
\hline Male & 62,235 & $17,459(28.1)$ & $44,776(71.9)$ & $0.98(0.96-1.00)$ & 0.02 \\
\hline \multicolumn{6}{|l|}{ Age (yr) } \\
\hline $35-44$ & 12,091 & $3,230(26.7)$ & $8,861(73.3)$ & $1.05(1.04-1.07)$ & $<0.001$ \\
\hline$\geq 45$ & 6,223 & $1,807(29.0)$ & $4,416(71.0)$ & $1.02(1.00-1.04)$ & 0.05 \\
\hline \multicolumn{6}{|l|}{ Race/Ethnicity } \\
\hline Non-White & 30,134 & $8,361(27.7)$ & 21,773 (72.3) & 1.00 (ref) & - \\
\hline White & 35,955 & $10,114(28.1)$ & $25,841(71.9)$ & $0.99(0.99-1.00)$ & 0.28 \\
\hline \multicolumn{6}{|l|}{ Rural vs Urban ${ }^{*}$} \\
\hline Urban or Suburban & 51,780 & $14,566(28.1)$ & $37,214(71.9)$ & 1.00 (ref) & - \\
\hline Rural or Isolated Rural & 14,309 & $3,909(27.3)$ & $10,400(72.7)$ & $1.01(1.00-1.02)$ & 0.05 \\
\hline \multicolumn{6}{|l|}{ Military Service } \\
\hline \multicolumn{6}{|l|}{ Military Branch } \\
\hline Army & 48,112 & $12,972(27.0)$ & $35,140(73.0)$ & 1.00 (ref) & - \\
\hline Air Force & 2,235 & 700 (31.3) & $1,535(68.7)$ & $0.94(0.91-0.97)$ & $<0.001$ \\
\hline Marine Corps & 11,999 & $3,597(30.0)$ & $8,402(70.0)$ & $0.96(0.95-0.97)$ & $<0.001$ \\
\hline Navy & 3,743 & $1,206(32.2)$ & $2,537(67.8)$ & $0.93(0.91-0.95)$ & $<0.001$ \\
\hline \multicolumn{6}{|l|}{ Component Type } \\
\hline Active Duty & 40,197 & $11,048(27.5)$ & $29,149(72.5)$ & 1.00 (ref) & - \\
\hline National Guard/Reserves & 25,892 & 7,427 (28.7) & 18,465 (71.3) & $0.98(0.97-0.99)$ & 0.001 \\
\hline 1 & 35,103 & 9,359 (26.7) & $25,744(73.3)$ & 1.00 (ref) & - \\
\hline$\geq 2$ & 30,986 & $9,116(29.4)$ & $21,870(70.6)$ & $0.96(0.95-0.97)$ & $<0.001$ \\
\hline \multicolumn{6}{|c|}{ Other Health Problems and Medications } \\
\hline \multicolumn{6}{|l|}{ Alcohol Abuse or Dependence } \\
\hline No & 51,986 & $15,681(30.2)$ & $36,305(69.8)$ & 1.00 (ref) & - \\
\hline Yes & 14,103 & $2,794(19.8)$ & $11,309(80.2)$ & $1.15(1.14-1.16)$ & $<0.001$ \\
\hline \multicolumn{6}{|l|}{ Drug Abuse or Dependence } \\
\hline No & 58,708 & $17,228(29.3)$ & $41,480(70.7)$ & 1.00 (ref) & - \\
\hline Yes & 7,381 & $1,247(16.9)$ & $6,134(83.1)$ & $1.18(1.16-1.19)$ & $<0.001$ \\
\hline \multicolumn{6}{|l|}{ Opioid Medication } \\
\hline No & 46,950 & $14,188(30.2)$ & $32,762(69.8)$ & 1.00 (ref) & - \\
\hline Yes & 19,139 & $4,287(22.4)$ & $14,852(77.6)$ & $1.11(1.10-1.12)$ & $<0.001$ \\
\hline \multicolumn{6}{|c|}{ Benzodiazepine or Sedative-Hypnotic Medication } \\
\hline No & 43,245 & $14,082(32.6)$ & $29,163(67.4)$ & 1.00 (ref) & - \\
\hline Yes & 22,844 & $4,393(19.2)$ & $18,451(80.8)$ & $1.20(1.19-1.21)$ & $<0.001$ \\
\hline
\end{tabular}


JRRD, Volume 53, Number 2, 2016

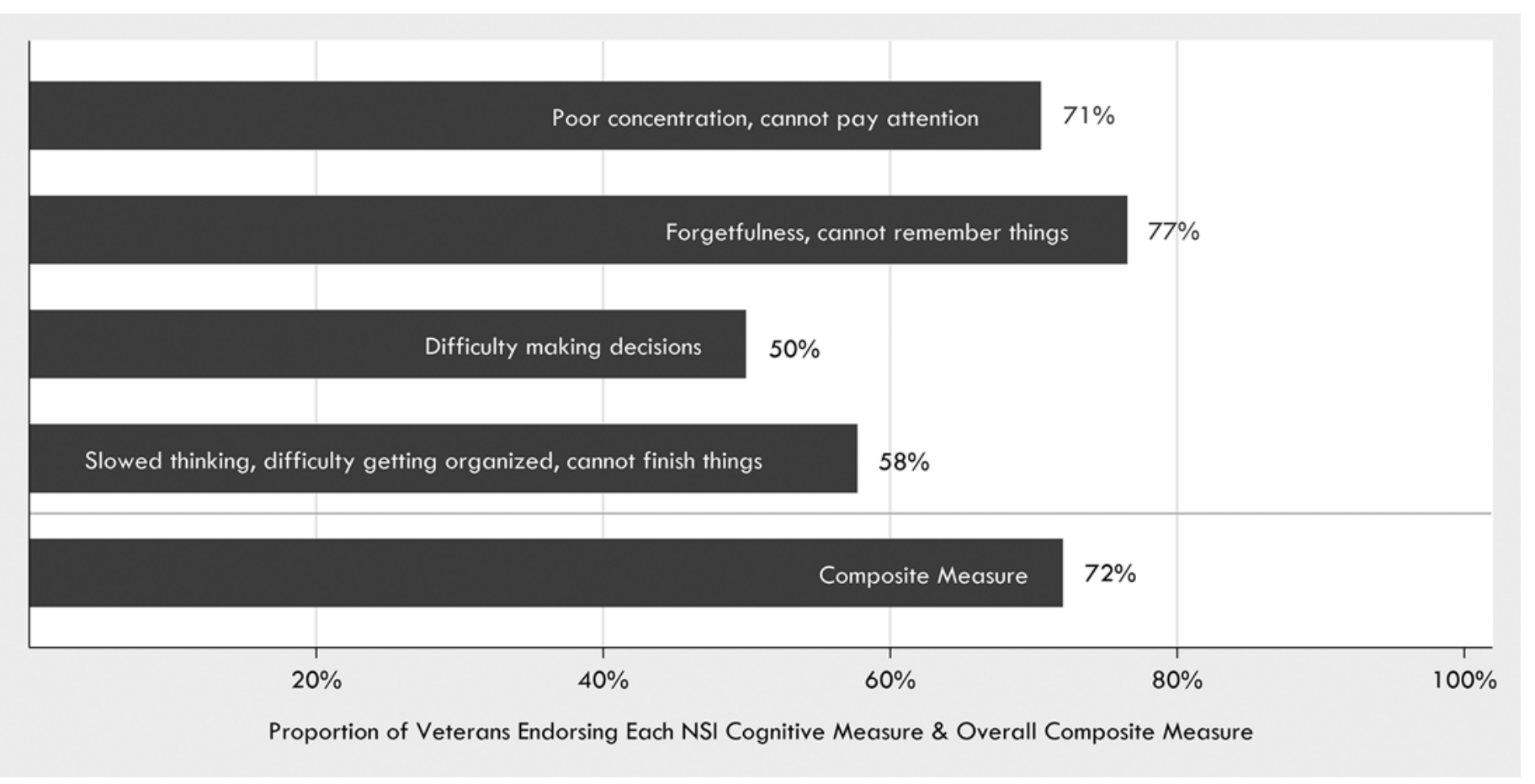

Figure 2.

Proportion of Veterans endorsing each of four cognitive symptoms on Neurobehavioral Symptoms Inventory (NSI) at level of moderate to very severe in terms of disruption of daily functioning, as well as proportion that is positive on binary composite variable, i.e., patients who endorse at least two of four NSI symptoms at level of moderate to very severe. As shown here, majority of Veterans who have screened positive on first-level traumatic brain injury (TBI) screen and undergo Comprehensive TBI Screening and Evaluation report moderate to very severe cognitive dysfunction.

$(\mathrm{ARR}=1.68)$; and the greatest risk in Veterans with PTSD, depression, and confirmed mTBI $($ ARR $=1.88)$, suggesting a weakly additive but independent effect of mTBI on cognitive symptoms. We also found that the independent effect of confirmed mTBI in the presence of PTSD and depression represented a smaller ARR of 1.12 (95\% CI $=1.11-1.13)$, explained by modest but significant negative interaction that mitigates the purely additive effect of mTBI on PTSD and depression in association with self-reported moderate to very severe cognitive impairment.

\section{DISCUSSION}

To our knowledge, this is the first study to focus on perceived cognitive dysfunction in a national sample of OIF/OEF Veterans in VA healthcare undergoing comprehensive TBI evaluation after a positive first-level TBI screen. In this relatively young population of Veterans (median age of 28), 72 percent of all Veterans who ini- tially screened positive for mTBI on the VA first-level screen reported moderate to very severe cognitive impairment that interfered with daily activities during the comprehensive evaluation. This included 42 percent of Veterans who were positive on the first-level TBI screen but, when evaluated by a VA TBI expert, were found not to have sustained a combat-related mTBI. While only 11.8 percent of Veterans received a diagnosis of confirmed mTBI alone (without comorbid mental health problems), the majority received diagnoses of mTBI in association with one or more mental health diagnoses (70.0\% PTSD and 45.8\% depression), alcohol and drug use disorder diagnoses, and opioid pain medications and/ or benzodiazepine/sedative hypnotics prescriptions. Each of these non-TBI variables was also independently associated with increased risk for reporting moderate to very severe cognitive impairment. Indeed, in the case of either PTSD or depression as the sole diagnosis, the association with perceived cognitive impairment was greater than that associated with confirmed mTBI diagnoses. 


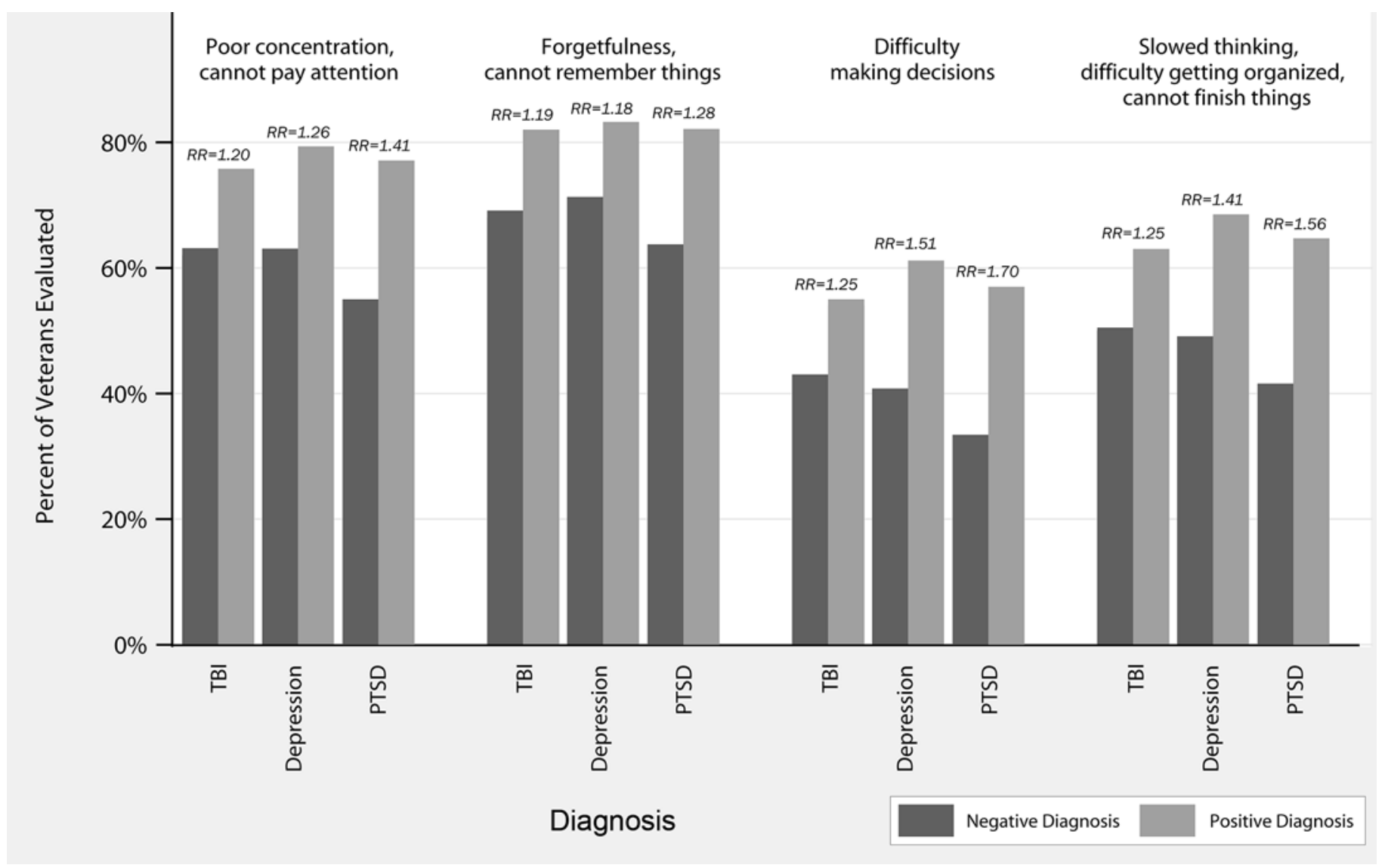

Figure 3.

Graphical representation of adjusted relative risks (RRs) of Veterans' reporting moderate to very severe cognitive dysfunction in association with different combinations of mild traumatic brain injury (TBI), posttraumatic stress disorder (PTSD), and depression to examine interactive and additive effects of each of these disorders. Graph shows clear progression of self-reported moderate to very severe cognitive impairment with lowest risk in Veterans with mild TBI alone, greater risk in those with PTSD and depression, and only slightly increased risk for cognitive impairment in Veterans who have mild TBI in addition to PTSD and depression.

Memory and attention problems were commonly reported by Gulf war Veterans [25]. Historically, Veterans returning from war have reported cognitive complaints, which, in the vast majority of cases, are not attributable to TBI [26-27]. Cognitive postconcussive symptoms often lack objective neurocognitive findings, and studies in civilians have shown that these symptoms occur at similar rates in persons with mTBI as in those with no TBI [2829]. More recently, Polusny et al. showed that deployment-related mTBI was significantly associated with two self-reported cognitive outcomes (memory and concentration problems) among National Guard servicemembers deployed to Iraq [30]. In this same study, in the group of servicemembers with PTSD and mTBI, when PTSD was entered into a multivariate logistic regression model, mTBI was no longer significantly associated with these two cognitive outcomes, suggesting that PTSD confounded the apparent relationship between TBI and selfreported cognitive impairment [30].

Our unadjusted analyses revealed a predominance of comorbid diagnosed mTBI, depression, and PTSD in this population of Veterans. In addition, it did not fit with our clinical experience (in which these conditions commonly co-occur) to perform a simple adjustment for PTSD and depression when evaluating the association between confirmed mTBI and cognitive impairment, since these diagnoses typically occur together. In fact, when we examined each of the four cognitive symptoms (e.g., forgetfulness, 
Table 3.

Independent association of self-reported moderate to very severe cognitive dysfunction with mental disorder diagnoses in 66,089 Iraq and Afghanistan Veterans who screened positive for traumatic brain injury (TBI) and completed comprehensive TBI evaluation (April 14, 2007-May 31, 2012).

\begin{tabular}{|c|c|c|c|c|}
\hline $\begin{array}{c}\text { Diagnosis } \\
\text { (Mutually Exclusive) }\end{array}$ & $\begin{array}{l}\text { Base Model, RR } \\
\text { (95\% CI) }\end{array}$ & $\begin{array}{c}\text { With Sociodemographic } \\
\text { and Military Service } \\
\text { Characteristics, ARR } \\
\text { (95\% CI) }\end{array}$ & $\begin{array}{c}\text { With DUD and AUD } \\
\text { Diagnoses, ARR } \\
(95 \% \mathrm{CI})\end{array}$ & $\begin{array}{l}\text { With Medications, } \\
\text { ARR (95\% CI) }\end{array}$ \\
\hline No Diagnosis & 1.00 (ref) & 1.00 (ref) & 1.00 (ref) & 1.00 (ref) \\
\hline Confirmed TBI & 1.35 (1.31-1.39) & $1.36(1.31-1.40)$ & $1.36(1.32-1.40)$ & $1.35(1.31-1.40)$ \\
\hline PTSD & $1.50(1.45-1.54)$ & $1.49(1.45-1.54)$ & $1.48(1.44-1.53)$ & $1.46(1.42-1.50)$ \\
\hline Depression & $1.52(1.46-1.58)$ & $1.51(1.46-1.57)$ & $1.50(1.44-1.56)$ & $1.48(1.43-1.54)$ \\
\hline Confirmed TBI and Depression & $1.70(1.64-1.76)$ & $1.69(1.63-1.75)$ & $1.68(1.62-1.74)$ & $1.66(1.60-1.72)$ \\
\hline Confirmed TBI and PTSD & $1.79(1.74-1.84)$ & $1.79(1.74-1.84)$ & $1.78(1.73-1.83)$ & $1.74(1.69-1.79)$ \\
\hline PTSD and Depression & $1.77(1.72-1.82)$ & $1.76(1.71-1.81)$ & $1.73(1.68-1.78)$ & $1.68(1.63-1.73)$ \\
\hline $\begin{array}{l}\text { Confirmed TBI, PTSD, and } \\
\text { Depression }\end{array}$ & $1.98(1.93-2.04)$ & $1.97(1.92-2.03)$ & $1.94(1.89-1.99)$ & $1.88(1.83-1.93)$ \\
\hline
\end{tabular}

cannot remember things) because of the high comorbidity rate, we found only minor differences between PTSD, depression, and mTBI with respect to their association with each. Thus, we designed our final analysis to explore the additive and interactive effects of PTSD, depression, and confirmed mTBI with regard to moderate to very severe cognitive impairment, which departs from the analytic design of prior studies [2,12,30]. In analyses adjusted in stepwise fashion for sociodemographic characteristics and other potential confounders (Table 3), we did find a slight independent increased risk of self-reported cognitive impairment in Veterans with mTBI only (compared with no mental disorders). Notably, however, the association of cognitive impairment was higher in Veterans with PTSD only, depression only, and comorbid PTSD and depression than with mTBI only. In fact, mTBI had only a very modest additional effect on cognitive impairment when it co-occurred with PTSD and depression.

Self-reported cognitive symptoms following mTBI have been shown to be poorly associated with neuropsychological performance in combat Veterans [26-27,31]. Moreover, neuropsychological deficits following mTBI typically resolve in weeks to months following the injury [32]. In contrast, several studies have demonstrated that mental health disorders, particularly PTSD and depression, are associated not only with cognitive postconcussive symptoms but also with objective cognitive impairment on performance-based tests, including deficits in attention, verbal learning and memory, processing speed, working memory, and inhibitory control [32-34]. Neuroimaging studies have mapped PTSD-related cognitive deficits to specific brain regions, namely the ventromedial and ventrolateral prefrontal cortex and hippocampus [35]. Unlike neuropsychological deficits associated with mTBI, those associated with PTSD tend to persist [32]. Most evidence-based cognitive behavioral therapy for PTSD and depression does not include cognitive remediation, and specifically treating cognitive deficits may render these therapies more effective in individuals with cognitive dysfunction [36].

The VA TBI screening process is nonspecific for deployment-related mTBI, because it not only screens for a historical TBI event with symptoms but also casts a broad net in that it assesses for a wide range of postdeployment symptoms, including cognitive problems. Thus, the TBI screen, in part, fulfills the intended goal of population-based screening in detecting postdeployment problems if they are present and has been shown to lead to increased VA care utilization, although we do not know whether this care was appropriate or indicated [37]. At the same time, the TBI screen may be too nonspecific and have unintended iatrogenic consequences as argued by Hoge et al., who raise the concern that the current TBI screening process may result in the misattribution of cognitive and other postconcussive symptoms to mTBI, when in fact, these problems are more likely due to conditions 
and diagnoses other than mTBI [38-39]. This may not only heighten anxiety about TBI, but also make the path to appropriate treatment more convoluted, delaying recovery [38]. Whereas TBI with sustained postconcussive symptoms carries a poor prognosis and is challenging to treat, other causes of postinjury cognitive symptoms, such as mental health problems, may be remediable by using evidence-based psychotherapies, using medications, or conveying positive recovery expectations [40].

Several limitations apply to our findings. First, our results may not generalize to all OIF/OEF Veterans. Of the 111,503 Veterans who screened positive on the firstlevel TBI screen, only a little more than half underwent comprehensive evaluation, and those who screened negative on the first-level TBI screen were not evaluated further for cognitive symptoms. Thus, these two potentially important groups were excluded because of the structure of the VA TBI screening process. Second, whereas we used the gold standard clinical diagnosis of mTBI (among those completing the comprehensive TBI evaluation), we relied on administrative data for mental health diagnoses (PTSD and depression). This limitation was partially offset by including only Veterans who received mental health diagnoses on at least two or more clinical visits. Third, the main study outcome relies on self-report data. Our data showed a significant positive correlation between severity of TBI injury and self-reported level of cognitive dysfunction. Nevertheless, O'Connor et al. and Prouteau et al. showed that individuals with depression tend to exaggerate their cognitive deficits and that selfreport measures used to assess cognitive functioning may not correlate with objective cognitive performance [4142]. French et al. also showed a poor correlation between cognitive complaints and objective neuropsychological test performance in military personnel with TBI [31]. Fourth, our data were cross-sectional, and thus, we can only examine relative associations of mTBI, depression, and PTSD with cognitive dysfunction but cannot assume causality. In fact, without premorbid information about cognitive functioning, we cannot evaluate whether diminished cognitive capacity that was either congenital or acquired from a prior TBI rendered Veterans more susceptible to the development of subsequent PTSD, depression, or a second deployment-related TBI due to reduced cognitive reserves and problem-solving capacity [39]. Fifth, the high coprevalence of TBI, depression, and PTSD, all of which may contribute variance to postconcussive symptoms, may inflate estimates of the correla- tion between each disorder and postconcussive symptoms. Finally, the high prevalence of cognitive impairment symptoms throughout this cohort may have limited our ability to differentiate the relative contributions of PTSD, depression, and mTBI because it resulted in a "ceiling effect" of the maximum RR that we could potentially observe.

\section{CONCLUSIONS}

Despite these limitations, our findings point to some potential issues related to the current VA TBI screening process. Within the current VA TBI screening algorithm, self-reported cognitive dysfunction is only assessed in the group that screens positive for mTBI (in primary care) and follows up and completes a comprehensive TBI evaluation in a specialty clinic at some time in the future. This can result in some Veterans not being evaluated; others lost to follow-up; and because of the framing of the TBI screening program, some Veterans misattributing cognitive problems to TBI as opposed to mental health problems, potentially delaying appropriate therapy. In addition, the 4-item VA first-level TBI screen is nonspecific in that the majority of Veterans who screen positive for mTBI report moderate to very severe cognitive impairment, yet a significant proportion is found not to have mTBI on comprehensive examination, and selfreported cognitive dysfunction is more strongly associated with mental health problems than with mTBI.

In conclusion, Veterans with comorbid mental health problems with and without TBI frequently report cognitive problems such as problems with attention, concentration, and memory. Mental health treatment for conditions such as PTSD and depression, in which cognitive dysfunction is often a symptom, may in itself ameliorate cognitive impairment. In addition, mental health clinicians treating Veterans with and without TBI can assess, treat, and provide support for distress related to poor cognitive functioning.

\section{ACKNOWLEDGMENTS}

\section{Author Contributions:}

Study concept and design: K. H. Seal, K. Samuelson, J. J. Vasterling. Literature search: S. Kumar.

Analysis and interpretation of data: K. H. Seal, D. Berthenthal, K. Samuelson, S. Maguen, J. J. Vasterling. 
Drafting of manuscript: K. H. Seal, D. Berthenthal, S. Kumar. Critical revision of manuscript for important intellectual content: K. Samuelson, S. Maguen, J. J. Vasterling.

Statistical analysis: D. Berthenthal.

Financial Disclosures: The authors have declared that no competing interests exist.

Funding/Support: This material was based on work supported by VA Health Services Research and Development (award SDR-08-408).

Additional Contributions: We gratefully acknowledge the service of the men and women who served in the Iraq and Afghanistan conflicts as well as those who continue to serve today. Dr. Samuelson is now with the University of Colorado at Colorado Springs, Colorado Springs, Colorado.

Institutional Review: This study was approved by the University of California, San Francisco, Committee on Human Research and by the San Francisco VA Medical Center. Since retrospective administrative data were used for this study, both a Health Insurance Portability and Accountability Act waiver of authorization and a waiver of informed consent were obtained.

Participant Follow-up: The authors have no plans to notify the study subjects of the publication of this article because of a lack of contact information.

\section{REFERENCES}

1. Okie S. Traumatic brain injury in the war zone. $\mathrm{N}$ Engl $\mathrm{J}$ Med. 2005;352(20):2043-47. [PMID:15901856] http://dx.doi.org/10.1056/NEJMp058102

2. Hoge CW, McGurk D, Thomas JL, Cox AL, Engel CC, Castro CA. Mild traumatic brain injury in U.S. soldiers returning from Iraq. N Engl J Med. 2008;358(5):453-63. [PMID:18234750] http://dx.doi.org/10.1056/NEJMoa072972

3. Terrio H, Brenner LA, Ivins BJ, Cho JM, Helmick K, Schwab K, Scally K, Bretthauer R, Warden D. Traumatic brain injury screening: Preliminary findings in a US Army Brigade Combat Team. J Head Trauma Rehabil. 2009; 24(1):14-23. [PMID:19158592] http://dx.doi.org/10.1097/HTR.0b013e31819581d8

4. National Center for Injury Prevention and Control. Report to Congress on mild traumatic brain injury in the United States: Steps to prevent a serious public health problem. Atlanta (GA): Centers for Disease Control and Prevention; 2003.

5. Chamelian L, Feinstein A. Outcome after mild to moderate traumatic brain injury: The role of dizziness. Arch Phys Med Rehabil. 2004;85(10):1662-66. [PMID:15468028] http://dx.doi.org/10.1016/j.apmr.2004.02.012

6. Bleiberg J, Cernich AN, Cameron K, Sun W, Peck K, Ecklund PJ, Reeves D, Uhorchak J, Sparling MB, Warden DL. Duration of cognitive impairment after sports concussion. Neurosurgery. 2004;54(5):1073-78, discussion 1078-80. [PMID:15113460] http://dx.doi.org/10.1227/01.NEU.0000118820.33396.6A
7. Levin HS, Mattis S, Ruff RM, Eisenberg HM, Marshall LF, Tabaddor K, High WM Jr, Frankowski RF. Neurobehavioral outcome following minor head injury: A three-center study. J Neurosurg. 1987;66(2):234-43. [PMID:3806205] http://dx.doi.org/10.3171/jns.1987.66.2.0234

8. Vanderploeg RD, Curtiss G, Luis CA, Salazar AM. Longterm morbidities following self-reported mild traumatic brain injury. J Clin Exp Neuropsychol. 2007;29(6):585-98. [PMID:17691031] http://dx.doi.org/10.1080/13803390600826587

9. McCrea MA. Mild traumatic brain injury and postconcussion syndrome: The new evidence base for diagnosis and treatment. New York (NY): Oxford University Press; 2008.

10. Ruff R. Two decades of advances in understanding of mild traumatic brain injury. J Head Trauma Rehabil. 2005;20(1): 5-18. [PMID:15668567] http://dx.doi.org/10.1097/00001199-200501000-00003

11. Carlson KF, Nelson D, Orazem RJ, Nugent S, Cifu DX, Sayer NA. Psychiatric diagnoses among Iraq and Afghanistan war veterans screened for deployment-related traumatic brain injury. J Trauma Stress. 2010;23(1):17-24. [PMID:20127725]

12. Schneiderman AI, Braver ER, Kang HK. Understanding sequelae of injury mechanisms and mild traumatic brain injury incurred during the conflicts in Iraq and Afghanistan: Persistent postconcussive symptoms and posttraumatic stress disorder. Am J Epidemiol. 2008;167(12): 1446-52. [PMID:18424429] http://dx.doi.org/10.1093/aje/kwn068

13. Marx BP, Brailey K, Proctor SP, Macdonald HZ, Graefe AC, Amoroso P, Heeren T, Vasterling JJ. Association of time since deployment, combat intensity, and posttraumatic stress symptoms with neuropsychological outcomes following Iraq war deployment. Arch Gen Psychiatry. 2009; 66(9):996-1004. [PMID:19736356] http://dx.doi.org/10.1001/archgenpsychiatry.2009.109

14. Iverson GL. Misdiagnosis of the persistent postconcussion syndrome in patients with depression. Arch Clin Neuropsychol. 2006;21(4):303-10. [PMID:16797916] http://dx.doi.org/10.1016/j.acn.2005.12.008

15. Gunstad J, Suhr JA. Cognitive factors in Postconcussion Syndrome symptom report. Arch Clin Neuropsychol. 2004; 19(3):391-405. [PMID:15033224] http://dx.doi.org/10.1016/S0887-6177(03)00073-8

16. Maguen S, Lau KM, Madden E, Seal K. Relationship of screen-based symptoms for mild traumatic brain injury and mental health problems in Iraq and Afghanistan veterans: Distinct or overlapping symptoms? J Rehabil Res Dev. 2012; 49(7):1115-26. [PMID:23341283] http://dx.doi.org/10.1682/JRRD.2011.02.0015

17. Donnelly KT, Donnelly JP, Dunnam M, Warner GC, Kittleson CJ, Constance JE, Bradshaw CB, Alt M. Reliability, 
sensitivity, and specificity of the VA traumatic brain injury screening tool. J Head Trauma Rehabil. 2011;26(6):439-53. [PMID:21386716] http://dx.doi.org/10.1097/HTR.0b013e3182005de3

18. Veterans Health Administration. Screening and evaluation of possible traumatic brain injury in Operation Enduring Freedom (OEF) and Operation Iraqi Freedom (OIF) Veterans. VHA Directive 2007-13. Washington (DC): Department of Veterans Affairs; 2007 Apr 13.

19. Cicerone KD, Kalmar K. Persistent postconcussion syndrome: The structure of subjective complaints after mild traumatic brain injury. J Head Trauma Rehabil. 1995; 10(3):1-17.

http://dx.doi.org/10.1097/00001199-199510030-00002

20. Lozano D, Gonzales-Portillo GS, Acosta S, de la Pena I, Tajiri N, Kaneko Y, Borlongan CV. Neuroinflammatory responses to traumatic brain injury: Etiology, clinical consequences, and therapeutic opportunities. Neuropsychiatr Dis Treat. 2015;11:97-106. [PMID:25657582]

21. Chauhan NB. Chronic neurodegenerative consequences of traumatic brain injury. Restor Neurol Neurosci. 2014;32(2): 337-65. [PMID:24398724]

22. Powner DJ, Boccalandro C, Alp MS, Vollmer DG. Endocrine failure after traumatic brain injury in adults. Neurocrit Care. 2006;5(1):61-70. [PMID:16960299] http://dx.doi.org/10.1385/NCC:5:1:61

23. Warriner EM, Velikonja D. Psychiatric disturbances after traumatic brain injury: Neurobehavioral and personality changes. Curr Psychiatry Rep. 2006;8(1):73-80.

[PMID:16513045]

http://dx.doi.org/10.1007/s11920-006-0083-2

24. Meterko M, Baker E, Stolzmann KL, Hendricks AM, Cicerone KD, Lew HL. Psychometric assessment of the Neurobehavioral Symptom Inventory-22: The structure of persistent postconcussive symptoms following deployment-related mild traumatic brain injury among veterans. J Head Trauma Rehabil. 2012;27(1):55-62.

[PMID:22190009] http://dx.doi.org/10.1097/HTR.0b013e318230fb17

25. Kang HK, Mahan CM, Lee KY, Magee CA, Murphy FM. Illnesses among United States veterans of the Gulf War: A population-based survey of 30,000 veterans. J Occup Environ Med. 2000;42(5):491-501. [PMID:10824302] http://dx.doi.org/10.1097/00043764-200005000-00006

26. Spencer RJ, Drag LL, Walker SJ, Bieliauskas LA. Selfreported cognitive symptoms following mild traumatic brain injury are poorly associated with neuropsychological performance in OIF/OEF veterans. J Rehabil Res Dev. 2010;47(6):521-30. [PMID:20848365]

http://dx.doi.org/10.1682/JRRD.2009.11.0181

27. Stulemeijer M, Vos PE, Bleijenberg G, van der Werf SP. Cognitive complaints after mild traumatic brain injury: Things are not always what they seem. J Psychosom Res.
2007;63(6):637-45. [PMID:18061755]

http://dx.doi.org/10.1016/j.jpsychores.2007.06.023

28. Meares S, Shores EA, Taylor AJ, Batchelor J, Bryant RA, Baguley IJ, Chapman J, Gurka J, Dawson K, Capon L, Marosszeky JE. Mild traumatic brain injury does not predict acute postconcussion syndrome. J Neurol Neurosurg Psychiatry. 2008;79(3):300-306. [PMID:17702772] http://dx.doi.org/10.1136/jnnp.2007.126565

29. Iverson GL, Lange RT. Examination of "postconcussionlike” symptoms in a healthy sample. Appl Neuropsychol. 2003;10(3):137-44. [PMID:12890639] http://dx.doi.org/10.1207/S15324826AN1003_02

30. Polusny MA, Kehle SM, Nelson NW, Erbes CR, Arbisi PA, Thuras P. Longitudinal effects of mild traumatic brain injury and posttraumatic stress disorder comorbidity on postdeployment outcomes in National Guard soldiers deployed to Iraq. Arch Gen Psychiatry. 2011;68(1):79-89. [PMID:21199967] http://dx.doi.org/10.1001/archgenpsychiatry.2010.172

31. French LM, Lange RT, Brickell T. Subjective cognitive complaints and neuropsychological test performance following military-related traumatic brain injury. J Rehabil Res Dev. 2014;51(6):933-50. [PMID:25479042]

http://dx.doi.org/10.1682/JRRD.2013.10.0226

32. Vasterling JJ, Verfaellie $M$. Introduction-posttraumatic stress disorder: A neurocognitive perspective. J Int Neuropsychol Soc. 2009;15(6):826-29. [PMID:19891816] http://dx.doi.org/10.1017/S1355617709990683

33. Vasterling JJ, Brailey K, Proctor SP, Kane R, Heeren T, Franz M. Neuropsychological outcomes of mild traumatic brain injury, post-traumatic stress disorder and depression in Iraq-deployed US Army soldiers. Br J Psychiatry. 2012; 201(3):186-92. [PMID:22743844] http://dx.doi.org/10.1192/bjp.bp.111.096461

34. Samuelson KW, Neylan TC, Metzler TJ, Lenoci M, Rothlind J, Henn-Haase C, Choucroun G, Weiner MW, Marmar CR. Neuropsychological functioning in posttraumatic stress disorder and alcohol abuse. Neuropsychology. 2006; 20(6):716-26. [PMID:17100516] http://dx.doi.org/10.1037/0894-4105.20.6.716

35. Tischler L, Brand SR, Stavitsky K, Labinsky E, Newmark R, Grossman R, Buchsbaum MS, Yehuda R. The relationship between hippocampal volume and declarative memory in a population of combat veterans with and without PTSD. Ann N Y Acad Sci. 2006;1071:405-9. [PMID:16891587] http://dx.doi.org/10.1196/annals.1364.031

36. Tarrier N, Pilgrim H, Sommerfield C, Faragher B, Reynolds M, Graham E, Barrowclough C. A randomized trial of cognitive therapy and imaginal exposure in the treatment of chronic posttraumatic stress disorder. J Consult Clin Psychol. 1999;67(1):13-18. [PMID:10028204]

http://dx.doi.org/10.1037/0022-006X.67.1.13 
37. Hendricks AM, Amara J, Baker E, Charns MP, Gardner JA, Iverson KM, Kimerling R, Krengel M, Meterko M, Pogoda TK, Stolzmann KL, Lew HL. Screening for mild traumatic brain injury in OEF-OIF deployed US military: An empirical assessment of VHA's experience. Brain Inj. 2013;27(2): 125-34. [PMID:23384211] http://dx.doi.org/10.3109/02699052.2012.729284

38. Hoge CW, Goldberg HM, Castro CA. Care of war veterans with mild traumatic brain injury-flawed perspectives. N Engl J Med. 2009;360(16):1588-91. [PMID:19369664] http://dx.doi.org/10.1056/NEJMp0810606

39. Bryant RA. Disentangling mild traumatic brain injury and stress reactions. N Engl J Med. 2008;358(5):525-27. [PMID:18234757] http://dx.doi.org/10.1056/NEJMe078235

40. Mittenberg W, DiGiulio DV, Perrin S, Bass AE. Symptoms following mild head injury: Expectation as aetiology. J Neurol Neurosurg Psychiatry. 1992;55(3):200-204. [PMID:1564481] http://dx.doi.org/10.1136/jnnp.55.3.200

41. O’Connor DW, Pollitt PA, Roth M, Brook PB, Reiss BB. Memory complaints and impairment in normal, depressed, and demented elderly persons identified in a community survey. Arch Gen Psychiatry. 1990;47(3):224-27.

\section{[PMID:2306164]}

http://dx.doi.org/10.1001/archpsyc.1990.01810150024005

42. Prouteau A, Verdoux H, Briand C, Lesage A, Lalonde P, Nicole L, Reinharz D, Stip E. Self-assessed cognitive dysfunction and objective performance in outpatients with schizophrenia participating in a rehabilitation program. Schizophr Res. 2004;69(1):85-91. [PMID:15145474] http://dx.doi.org/10.1016/j.schres.2003.08.011

Submitted for publication December 1, 2014. Accepted in revised form June 25, 2015.

This article and any supplementary material should be cited as follows:

Seal KH, Bertenthal D, Samuelson K, Maguen S, Kumar $\mathrm{S}$, Vasterling JJ. Association between mild traumatic brain injury and mental health problems and self-reported cognitive function in Iraq and Afghanistan Veterans. J Rehabil Res Dev. 2016;53(2):185-98.

http://dx.doi.org/10.1682/JRRD.2014.12.0301

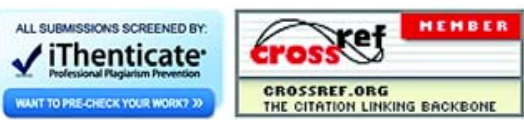

